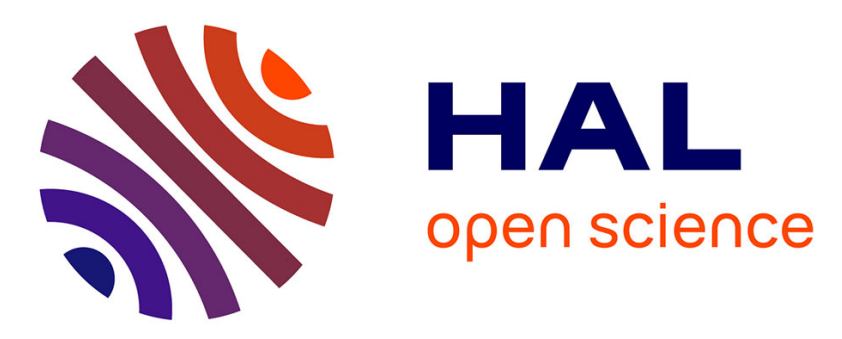

\title{
Stable dicationic dioxoliums and fate of their dioxolyl radicals
}

\author{
Marc Devillard, Vianney Regnier, Jacques Pécaut, David Martin
}

\section{To cite this version:}

Marc Devillard, Vianney Regnier, Jacques Pécaut, David Martin. Stable dicationic dioxoliums and fate of their dioxolyl radicals. Organic Chemistry Frontiers, 2019, 6 (18), pp.3184-3191. 10.1039/C9QO00298G . hal-02094850

\section{HAL Id: hal-02094850 \\ https://hal.science/hal-02094850}

Submitted on 28 Sep 2020

HAL is a multi-disciplinary open access archive for the deposit and dissemination of scientific research documents, whether they are published or not. The documents may come from teaching and research institutions in France or abroad, or from public or private research centers.
L'archive ouverte pluridisciplinaire HAL, est destinée au dépôt et à la diffusion de documents scientifiques de niveau recherche, publiés ou non, émanant des établissements d'enseignement et de recherche français ou étrangers, des laboratoires publics ou privés. 


\section{Stable Dicationic Dioxoliums and Fate of their Dioxolyl Radicals}

Marc Devillard, ${ }^{a}$ Vianney Regnier, ${ }^{a}$ Jacques Pecaut, ${ }^{b}$ and David Martin ${ }^{a}{ }^{a}$

${ }^{a}$ Univ. Grenoble Alpes, CNRS, DCM, 38000 Grenoble, France

${ }^{b}$ Univ. Grenoble Alpes, CEA, CNRS, INAC-SYMMES, UMR 581938000 Grenoble, France.

Abstract: Stable dicationic dioxolium salts featuring an ancillary vinamidinium pattern were synthesized and characterized. Although highly reactive, they were found otherwise easy to handle under inert atmosphere. This offered the opportunity to generate and study the fate of unknown 1,3-dioxolyl radicals. Depending on substituents, reduction led to the formation of dimers of either dioxolyl or cyclohexadienyl radicals, stemming from a process that is related to the Surzur-Tanner rearrangement. The cyclohexadienyl radical could be characterized in the case of a tri(tert-butyl)phenyl group, which prevents dimerization processes.

\section{Introduction}

The design of stabilized C-centered reactive molecules, such as carbeniums, carbanions or radicals, through the introduction of hetero-substituents is a well-proven concept. ${ }^{1-4}$ Indeed, the diversity of main group elements provides a wide palette of electronic effects, from prototypical $\pi$-accepting B- or Al-based functions, up to strong electron-donating amino groups. ${ }^{5}$ Oxygen stands out as the most electronegative element of the periodic table (apart from fluorine), ${ }^{5 a, b}$ while at the same time RO- alkoxy groups are almost equivalent to amino substituents in terms of $\pi$-donation. ${ }^{5}$ Strikingly, this combination isn't synergistic and the strong, but opposite, effects often counterbalance each other. In other words, the O-substituents fail to decrease the basicity of electron-rich carbanions because of their $+\mathrm{M}$ donation, ${ }^{3}$ whereas at the same time the electronegativity of oxygen prevent them for taming the reactivity of electron deficient carbenium centers. ${ }^{1,6}$ Thus, simple aryl- and alkyl-oxoniums are highly reactive and their study have been essentially confined to super acidic media. ${ }^{2,7}$ This is in marked contrast with their nitrogen counterparts: countless bench-stable iminiums and amidiniums have been reported. ${ }^{9}$ Similarly, the introduction of alkoxy groups have little beneficial effects on the stability of C-centered radicals. Even their combination with an electron-withdrawing group, so-called capto-dative substitution, ${ }^{4}$ results in modest enhancements, especially when compared to amino groups. As a matter of fact, to date, all isolated Cradicals with a simple capto-dative substitution pattern feature $\mathrm{N}$-substituents as donors. ${ }^{10,11}$

In this article, we consider the case of 1,3-dioxolyl scaffolds $\mathbf{A}$ (Scheme 1). Radicals $\mathbf{A}^{\bullet}$ have never been evidenced experimentally, ${ }^{12}$ although computational studies already assessed their possible role as reactive intermediates, especially in the rearrangement of $\beta$-(acyloxy)vinyl radicals. ${ }^{13-15}$ Note that known ${ }^{16}$ parented 1,3-dioxolanyl radicals $\mathbf{B}^{\bullet}$ should be similarly the intermediates in the shift of $\beta$-(acyloxy)alkyl radicals, so-called Surzur-Tanner rearrangement. ${ }^{17}$ However, extensive experimental and theoretical works have demonstrated that this reaction proceeds in fact through a closely-related transition state, which lies lower in energy (see Scheme 1). ${ }^{17 c, 18}$ Even more, the ester-shift doesn't occur in the case of ortho-(acyloxy)aryl radicals, neither through 1,3-benzodioxolyl radicals $\mathbf{C}^{\bullet}$ nor through another pathway, because of the inability of the aryl radical to achieve suitable orbital overlap. $^{19}$
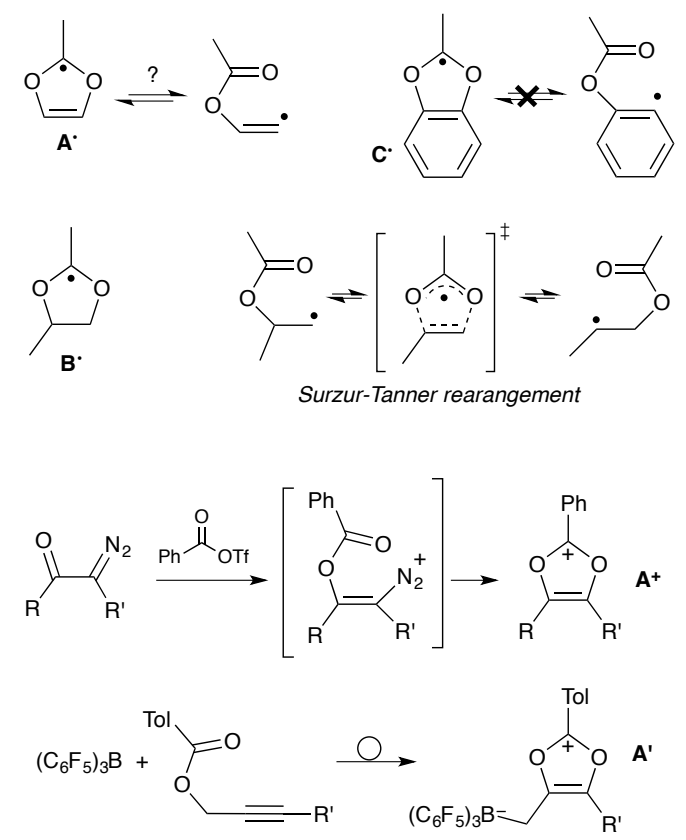

Scheme 1. Dioxolyl, dioxolanyl and benzodioxolyl radicals $A^{\circ}-C^{\circ}$; their relation with "Surzur-Tanner"-type rearrangements; synthesis of dioxoliums salts $\mathbf{A}^{+}$and $\mathbf{A}^{\prime}$. 
The absence of viable synthetic route towards the generation of $\mathbf{A}^{*}$ certainly explains why this class of radicals still constitutes a terra incognita. In principle, they could be unambiguously produced through one-electron reduction of the corresponding dioxolium salts $\mathbf{A}^{+}$. However, these carbeniums are highly reactive themselves, ${ }^{20,21}$ apart from derivatives benefiting from further stabilization, such as a benzo-fused ring ${ }^{22}$ or an additional heterosubstituent. ${ }^{23}$ Even in this latter case, attempts to assess the fate of the corresponding dioxolyl-like radicals were inconclusive. ${ }^{24}$ To date, only neutral zwitterrionic borate-based derivatives $\mathbf{A}^{\prime}$, which were recently prepared by Stephan et al. from prop-2-yn-1-yl benzoates, have been structurally characterized. ${ }^{21 \mathrm{~b}}$

Herein we report the synthesis of isolable dicationic dioxolium salts, featuring a vinamidinium pattern. Though reactive, they are easily handle-able under dry inert atmosphere. This allowed not only for full spectroscopic and structural characterizations, but also stepwise reactivity studies, especially the generation and fate of the corresponding cationic 1,3-dioxolyl radicals.

\section{Results and discussion}

This study was initially motivated by our interest in the reactivity of salt 1a (Scheme 2), in the context of our work on unusual vinamidinium scaffolds. ${ }^{25}$ The three-step synthesis of this novel synthon was straightforward. We first performed an iodide-catalyzed esterification of benzoic acid with $\mathrm{N}, \mathrm{N}$-(dimethyl)chloroacetamide. The resulting 2(benzoyloxy) acetamide $\mathbf{2 a}$ was reacted with dichloromethylene-dimethyl iminium chloride ${ }^{26}$ to yield, after anion metathesis, 1,3-(dichloro)vinamidinium hexafluorophosphate salt 3a. Finally, the addition of one equivalent of dimethyl(trimethylsilyl)amine allowed for a clean selective mono-substitution, affording 1 a in $78 \%$ yield.

Originally, we then wished to introduce a bulky anilino group by direct nucleophilic acyl substitution of the remaining chloride. A clean and complete reaction of $\mathbf{1 a}$ with $\mathbf{N}$-(trimethylsilyl)-2,6-di(isopropyl)aniline $\mathbf{4}$ was observed after 3 days at $60^{\circ} \mathrm{C}$ in acetonitrile (Scheme 3). However, whereas HR-MS analysis was consistent with the expected substitution product, the presence of a $\mathrm{C}-\mathrm{H}$ signal in ${ }^{13} \mathrm{C} N M R$ at $d=72.3 \mathrm{ppm}$ indicated the formation of a different structural isomer. A single crystal X-ray diffraction study finally allowed for the identification of benzimidate 5 (see supporting information). ${ }^{27}$

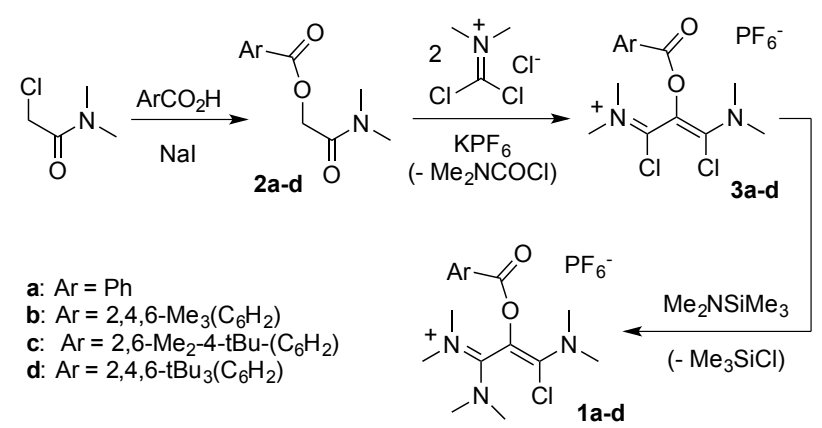

Scheme 2: Synthesis of 1-(chloro)vinamidinium salts 1a-d.

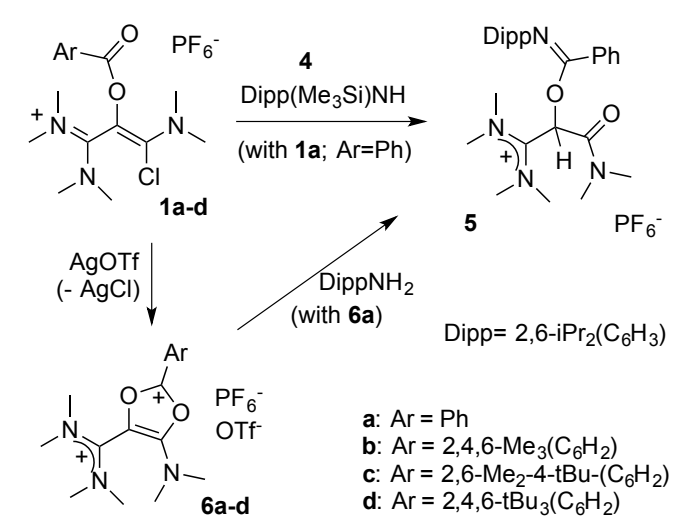

Scheme 3: Reaction of $1 \mathbf{a}$ with trimethylsilylanilines; synthesis of dioxolium salts 6 a-d.

The outcome of this reaction suggested the transient formation of dicationic 1,3-dioxolium 6 a, followed by fast aminolysis. ${ }^{20,21 a}$ In order to probe this hypothesis, a solution of 1a was stirred in presence of silver triflate. A bright yellow precipitate appeared, while NMR monitoring of the supernatant showed the gradual disappearance of the starting material with complete conversion after 2 days. The product was purified by crystallization and isolated in 
$56 \%$ yield. An X-ray diffraction analysis confirmed the formation of the dicationic dioxolium 6a (see further below).

We reacted $\mathbf{6 a}$ with 2,6-di(isopropyl)aniline and observed the formation of $\mathbf{5}$, as initially suggested by the reactivity of $1 \mathbf{a}$. As expected, $\mathbf{6 a}$ is also very sensitive to moisture and solubilization in tetrahydrofuran immediately triggers the oligomerization of the solvent. However, we found it otherwise easy to handle under inert atmosphere, which encouraged us to synthesize a set of parented dicationic dioxoliums $\mathbf{6 b}$-d, featuring methyl or tert-butyl groups in ortho and para positions of the aryl moieties. Starting from the corresponding benzoic acids, we synthesized 2-(aroyloxy)acetamide $\mathbf{2 b}$-d. Their reaction with dichloromethylenedimethyliminium chloride first performed very poorly, certainly due to the use of bulkier aryl substituents. Among several modifications to Viehe's original protocol, ${ }^{26}$ the use of acetonitrile as a solvent was found critical to finally isolate 1,3-di(chloro)vinamidinium salts $\mathbf{3 b - \mathbf { d }}$ in 44-62 \% yields. Next, treatment with dimethyl(trimethylsilyl)amine yielded 1 -chlorovinamidinium salts $\mathbf{1 b}$-d. As frequently observed for vinamidinium cations, 1a-d consist in mixtures of interconverting $E$ and $Z$ isomers, which can't be separated. Moreover, the conformers have distinct or fluxional ${ }^{13} \mathrm{C}$ and ${ }^{1} \mathrm{H}$ NMR signals at room temperature, resulting in equivocal spectra. We confirmed further their structure by X-ray diffraction analysis. Note that, in the solid state, 1a-c adopt a $Z$ configuration, which was therefore attributed to the most stable conformer, whereas both forms are present in the unit cell of $1 \mathbf{d}$. Finally, addition of one equivalent of silver triflate afforded the desired dicationic dioxoliums in $95-98 \%$ yield.

X-ray diffraction analysis of $\mathbf{6 a}$ and $\mathbf{6 c}$, for which suitable single crystals could be obtained, revealed similar structures for both dications (Figure 1 and Table 1). The $p$ interaction of oxygen atoms with the formal carbenium center is evident from the short C1-O bond lengths (6a: 1.286(2)/1.317(2) $\AA$; 6 c: $1.321(3) / 1.303(3) \AA$, which are typical values in saturated dioxolaniums ${ }^{28}$ and oxazolium salts) ${ }^{29}$ whereas C2-01 (6a: $1.397(2) \AA$; 6 c: $1.390(3) \AA$ ) and C3-02 (6a: 1.419(2) $\AA, 6 \mathrm{c}: 1.409$ (3) $\AA$ ) bond lengths are significantly longer. The aryl group and the dioxolium ring are nearly co-planar and their conjugation results in a rather short C1-C11 bond (1.429(3) $\AA$ in $6 a, c$, compared to 1.478(4) $\AA$ in 1a, and 1.492(10) and 1.506(9) $\AA$ in 1c for the two different molecules in the unit cell, respectively). From a structural point of view, the dioxolium patterns seem to have little influence on the vinamidinium moieties. In 6a, for instance, the C6-C3 (1.439(3) $\AA$ ) and C2-C3 (1.365(3) $\AA$ ) bond lengths are almost identical to those in corresponding acyclic precursor 1a (C6-C3: 1.440(4) $\AA$ and C3-C2: 1.370(5) $\AA$ ).
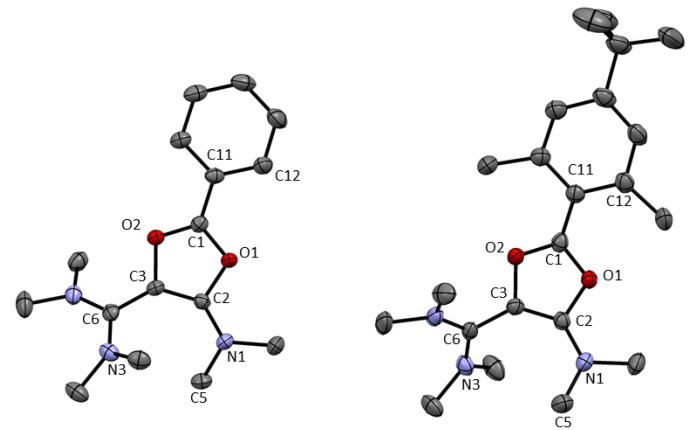

Figure 1: Representation of the X-ray structure of $\mathbf{6 a}$ and $\mathbf{6 c}$ with $50 \%$ probability ellipsoids. Counter-anions, hydrogen atoms and solvent are omitted for clarity. See Table 1 for key structural parameters.

Similarly, the ${ }^{13} \mathrm{C}$ NMR chemical shifts of C2/C6 (154.8-156.3 ppm) and C3 (113.1-114.5 ppm) in dioxoliums 6a-d parallel those in precursors 1a. They are fully consistent with polarized vinaminidinium moieties, featuring electron-rich $\mathrm{C} 3$ positions and electrophilic $\mathrm{C} 2 / \mathrm{C} 6$ centers. Overall, these data suggest only a modest interaction between the p-systems of the vinamidinium and the Aryl-C1-(O1O2) moieties. This is in line with previous findings that dioxoliums are not aromatic and their five membered ring is well described as a carbenium center stabilized by two oxygen atoms along with an isolated $\mathrm{C}=\mathrm{C}$ double bond. ${ }^{21}$

Of note, although spectroscopic data for $\mathbf{6 a - d}$ are overall analogous, alkyl substituents in ortho and para positions of the aryl group results in shielding the ipso carbon atom $\left({ }^{13} \mathrm{C} \mathrm{NMR}\right.$ chemical shift for $6 \mathbf{a}: d=117.3 \mathrm{ppm}$, for $\mathbf{6 b}-\mathrm{C}$ : $d=113.1 \mathrm{ppm})$. This is especially the case for $\mathbf{6 d}(d=108.3 \mathrm{ppm})$. In addition, $\mathbf{6 a - c}$ have almost identical ${ }^{13} \mathrm{C}$ NMR chemical shifts for the carbenium center $C 1(d=171.0-171.9 \mathrm{ppm})$, whereas the signal in $6 \mathrm{~d}$ is deshielded by 7 $\mathrm{ppm}$. We interpreted those slight, but significant, differences as the result of the twist around the $\mathrm{C} 1-\mathrm{C} 11$ bond in $\mathbf{6 d}$, due to the bulky tert-butyl ortho-substituents. A hypsochromic shift for the main UV-vis absorption band of $\mathbf{6 d}$ $(I=350 \mathrm{~nm}$, whereas for $6 \mathrm{a}-\mathrm{c}: I \approx 380 \mathrm{~nm})$ also supported a decrease in p-conjugation. 
Table 1: Key structural and spectroscopic parameters of dioxoliums 6a-d.

\begin{tabular}{|c|c|c|c|c|}
\hline & $6 a$ & $6 b$ & $6 c$ & $6 d$ \\
\hline \multicolumn{5}{|c|}{ Ar: $2,6-\mathrm{R}_{2}-4-\mathrm{R}^{\prime}\left(\mathrm{C}_{6} \mathrm{H}_{2}\right)$} \\
\hline $\mathrm{R}$ & $\mathrm{H}$ & Me & $\mathrm{Me}$ & $\mathrm{tBu}$ \\
\hline $\mathrm{R}^{\prime}$ & $\mathrm{H}$ & $\mathrm{Me}$ & $\mathrm{tBu}$ & $\mathrm{tBu}$ \\
\hline \multicolumn{5}{|l|}{ Bond lengths $(\AA)^{[a]}$} \\
\hline \multirow[t]{2}{*}{$\mathrm{C} 1-\mathrm{O} 1$} & $1.317(2)$ & - & $1.321(3)$ & - \\
\hline & $(1.3106)$ & (1.3196) & $(1.3192)$ & (1.3102) \\
\hline \multirow[t]{2}{*}{$\mathrm{C} 1-\mathrm{O} 2$} & $1.286(2)$ & - & $1.303(3)$ & - \\
\hline & (1.2821) & (1.2909) & $(1.2904)$ & $(1.2787)$ \\
\hline \multirow[t]{2}{*}{$\mathrm{O} 1-\mathrm{C} 2$} & $1.397(2)$ & - & $1.390(3)$ & - \\
\hline & $(1.3820)$ & $(1.3768)$ & $(1.3766)$ & (1.3816) \\
\hline \multirow[t]{2}{*}{$\mathrm{O} 2-\mathrm{C} 3$} & $1.419(2)$ & - & $1.409(3)$ & - \\
\hline & $(1.4041)$ & (1.4021) & $(1.4024)$ & (1.3959) \\
\hline \multirow[t]{2}{*}{$\mathrm{C} 2-\mathrm{C} 3$} & $1.365(3)$ & - & $1.365(3)$ & - \\
\hline & $(1.3730)$ & (1.3705) & $(1.3710)$ & $(1.3780)$ \\
\hline \multirow[t]{2}{*}{ C1-C11 } & $1.429(3)$ & - & $1.429(3)$ & - \\
\hline & $(1.4244)$ & (1.4189) & $(1.4194)$ & (1.4518) \\
\hline \multirow[t]{2}{*}{$\mathrm{C} 3-\mathrm{C} 6$} & $1.439(3)$ & - & $1.444(3)$ & - \\
\hline & $(1.4373)$ & (1.4349) & $(1.4355)$ & $(1.4417)$ \\
\hline \multirow[t]{2}{*}{$\mathrm{N} 1-\mathrm{C} 2$} & $1.312(2)$ & - & $1.319(3)$ & - \\
\hline & $(1.3120)$ & $(1.3135)$ & $(1.3134)$ & $(1.3098)$ \\
\hline \multicolumn{5}{|l|}{ Torsions $\left({ }^{\circ}\right)^{[a]}$} \\
\hline \multirow[t]{2}{*}{$\mathrm{O} 1-\mathrm{C} 1-\mathrm{C} 11-\mathrm{C} 12$} & $5.3(3)$ & - & $174.6(2)$ & - \\
\hline & $(1.2)$ & (1.8) & $(177.7)$ & (72.6) \\
\hline \multirow[t]{2}{*}{$\mathrm{O} 2-\mathrm{C} 3-\mathrm{C} 6-\mathrm{N} 2$} & $40.1(3)$ & - & $45.5(3)$ & - \\
\hline & $(44.4)$ & $(43.7)$ & $(43.7)$ & $(42.4)$ \\
\hline \multirow[t]{2}{*}{$\mathrm{C} 4-\mathrm{N} 1-\mathrm{C} 2-\mathrm{O} 1$} & $14.8(3)$ & - & $8.4(4)$ & - \\
\hline & $(15.7)$ & $(14.4)$ & $(13.8)$ & (12.9) \\
\hline \multicolumn{5}{|l|}{$d^{13} C N M R(p p m)$} \\
\hline $\mathrm{C} 1$ & 171.2 & 171.0 & 170.9 & 177.8 \\
\hline $\mathrm{C} 2$ & 156.3 & 156.1 & 156.1 & 155.9 \\
\hline C3 & 114.1 & 113.1 & 113.1 & 114.5 \\
\hline C6 & 155.5 & 155.8 & 155.8 & 154.8 \\
\hline $\mathrm{C} 11$ & 117.3 & 113.2 & 113.3 & 108.3 \\
\hline$I_{\max }$ UV-vis $(n m)^{[b]}$ & 380.0 & 381.0 & 383.0 & 352.0 \\
\hline$E_{p c}$ vs Fc/Fc+ $(\mathrm{V})^{[c]}$ & -1.06 & -1.12 & -1.11 & -1.17 \\
\hline
\end{tabular}

[a] From solid-state structures; values in brackets are from computed optimized structures, see supporting information. [b] In dichloromethane. [c] From cyclovoltammograms of solutions in acetonitrile $+(n-B u)_{4} N F_{6} 0.1 m$ mol. $^{-1}$ (carbon electrode, $\Phi=3 \mathrm{~mm}$; scan rate : $100 \mathrm{mV} \cdot \mathrm{s}^{-1}$ ).

Accordingly, the DFT-optimized structure of dication $6 \mathbf{d}$ features a large dihedral angle C12-C11-C1-01 of 73', whereas the dioxolium rings and the aryl groups are nearly coplanar in $\mathbf{6 a - c}$. The twisting in $\mathbf{6 d}$ results in a lengthening of the C1-C11 bond (6d: $1.452 \AA$; 6a-c: $1.419-1.429 \AA$ ).

Next, we examined the fate of these dications upon reduction. Cyclovoltammograms of all dioxoliums 6a-d feature an irreversible reduction wave at about -1.1 V. As a two-electron reduction would lead to an unreasonable "acetal anion" equivalent, we hypothesized an initial one-electron transfer. Note that no reversibility could be evidenced even at high scan rates (up to $10 \mathrm{~V} \cdot \mathrm{s}^{-1}$ ), thus indicating that the resulting radicals 7a-d must undergo a fast chemical transformation. 


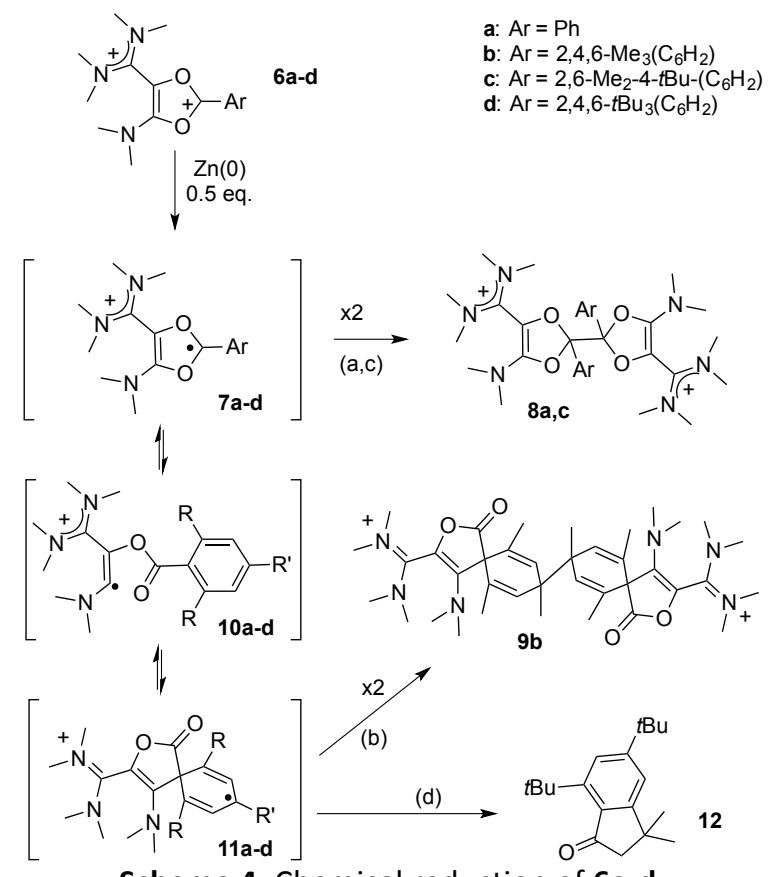

Scheme 4: Chemical reduction of $6 a-d$.

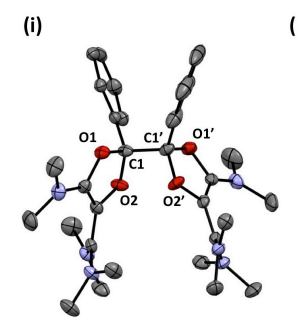

(ii)

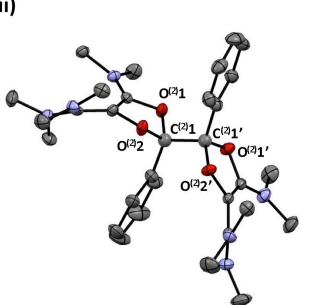

(iii)

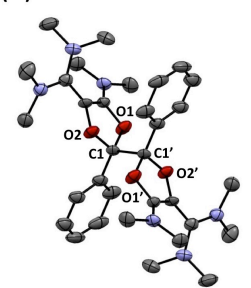

Figure 2: Representation of the X-ray structure of $d, I-8$ a (i: gauche conformer; ii: anti conformer) and meso-8a (iii) with 50\% probability ellipsoids. Counter-anions, hydrogen atoms and solvent are omitted for clarity.

In order to get further insight, we performed the chemical reductions of dioxolium salts $\mathbf{6 a - d}$. We first reacted $\mathbf{6 a}$ with half an equivalent of zinc powder. The monitoring of the reaction by ${ }^{1} \mathrm{H}$ NMR showed the gradual disappearance of $\mathbf{6 a}$ and the appearance of a new set of signals, while the reaction mixture remained EPR silent. At full conversion, the crude mixture consists in closely related isomers. Fractional crystallization allowed for the isolation of two diastereomeric forms of the dimer of dioxolyl radical 7a, the bis(dioxole)s $d, I-8$ a and meso-8a, in $53 \%$ and $7 \%$ yield respectively (Scheme 3 ). They were fully characterized and their structure was ascertained by $\mathrm{X}$-ray analysis (Figure 2). In the solid state, meso-8a displays a anti conformation of the two dioxolyl groups whereas both anti and gauche conformers are observed in the case of $d, I-8$ a.

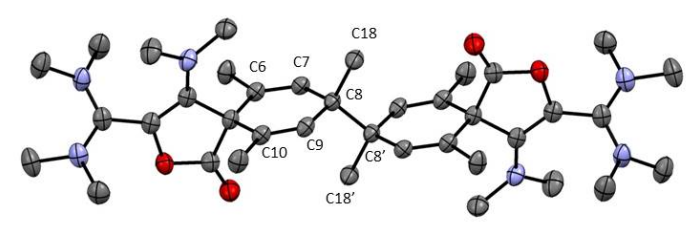

Figure 3: Representation of the X-ray structure of $\mathbf{9 b}$ with $50 \%$ probability ellipsoids. Counter-anions, hydrogen atoms and solvent are omitted for clarity.

Importantly, we couldn't evidence any reversible dissociation of the dimers. Neither $d, I-8$ a nor meso-8a afford equilibrated mixtures of diastereomers when heated in acetonitrile for several hours at $80{ }^{\circ} \mathrm{C}$. This indicates that Gibbs free activation energies for a $\mathrm{C}-\mathrm{C}$ bond breaking in dimers $8 \mathrm{a}$ are at least $30 \mathrm{kcal}^{\mathrm{mol}} \mathrm{m}^{-1}$. Note that DFT calculations $^{30}$ at the $\mathrm{uB} 3 \mathrm{LYP} / 6-311 \mathrm{~g}(\mathrm{~d}, \mathrm{p})$ level of theory failed to predict such a strong bond. For instance, the dimerization of $7 \mathrm{a}$ to afford the anti conformer of $d, I-8 \mathrm{a}$ is predicted to be endergonic by $\Delta \mathrm{G}=+12.1 \mathrm{kcal}^{\mathrm{mol}}{ }^{-1}$ and exergonic by only $-24 \mathrm{kcal}^{\mathrm{mol}}{ }^{-1}$ when introducing the Polarizing Continuum Model (PCM) for acetonitrile. As dispersion forces can play a critical role in the stability of such encumbered dimers, ${ }^{31}$ we considered the longrange corrected functional WB97XD, ${ }^{32}$ which implements a version of Grimme's D2 model for dispersion forces. ${ }^{33}$ As a matter of fact, the uwB97XD/6-311g(d,p)/PCM level of theory predicts a more exergonic dimerization $(\Delta \mathrm{G}=-$ 


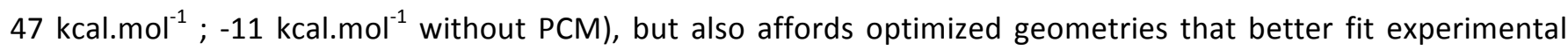

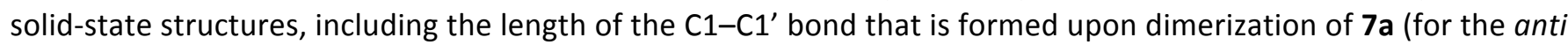
conformer of $d, I-8 \mathrm{a}$, B3LYP: $1.569 \AA$, wB97XD: $1.558 \AA$, X-ray: 155.2(4) $\AA$ ). For consistency throughout this work, all geometry optimizations were carried out at this level of theory. Note that the anti conformer of $d, I-8 \mathrm{a}$ was found more stable than the gauche conformer and than the meso diastereomer as well, but by only few kcal. $\mathrm{mol}^{-}$ ${ }^{1}$, in line with the experimental observation of the three forms.

Table 2: Gibbs free enthalpy of radical isomers $\mathbf{1 0}$ and $\mathbf{1 1}$ (relative to 7), and for the formation of dimers $\mathbf{8}$ and $\mathbf{9 .}$

\begin{tabular}{|c|c|c|c|c|}
\hline Dioxolyl radical & $7 a$ & $7 b$ & 7c & 7d \\
\hline $\mathrm{R}$ & $\mathrm{H}$ & $\mathrm{Me}$ & $\mathrm{Me}$ & $t \mathrm{Bu}$ \\
\hline $\mathrm{R}^{\prime}$ & $\mathrm{H}$ & $\mathrm{Me}$ & $t \mathrm{Bu}$ & $t \mathrm{Bu}$ \\
\hline \multicolumn{5}{|l|}{ Mulliken Spin density } \\
\hline $\mathrm{C} 1$ & $51 \%$ & $51 \%$ & $53 \%$ & $80 \%$ \\
\hline Aryl & $32 \%$ & $33 \%$ & $30 \%$ & $1 \%$ \\
\hline $\mathrm{O} 1$ and $\mathrm{O} 2$ & $13 \%$ & $12 \%$ & $12 \%$ & $15 \%$ \\
\hline \multicolumn{5}{|l|}{ 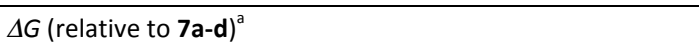 } \\
\hline $10 a-d$ & +1.0 & -1.6 & -0.8 & -0.8 \\
\hline 11a-d & -4.7 & -16.7 & -15.7 & -12.2 \\
\hline$[G(8 a-d)-G(9 a-d)]^{a}$ & -11.4 & +10.2 & -32.0 & n.a. ${ }^{b}$ \\
\hline \multicolumn{5}{|l|}{$\begin{array}{l}\Delta G(\text { dimer } \\
\text { formation) }{ }^{a}\end{array}$} \\
\hline $7 a-d(x 2) \rightarrow 8 a-d$ & -51.2 & -68.5 & -69.8 & n.a. ${ }^{b}$ \\
\hline $11 a-d(x 2) \rightarrow 9 a-d$ & -30.4 & -45.3 & -6.4 & +2.7 \\
\hline
\end{tabular}

We wondered whether replacing the phenyl group of $7 a$ with a bulkier 2,4,6-trimethylphenyl could prevent the dimerization of the corresponding dioxolyl radical $\mathbf{7 b}$ into the bis(dioxole) $\mathbf{8} \mathbf{b}$. Therefore, we performed the reduction of dication $6 \mathbf{b}$ with 0.5 equivalent of zinc. The ${ }^{1} \mathrm{H}$ NMR analysis of the crude mixture revealed the selective formation of a new compound $\mathbf{9 b}$ that could be isolated as yellow crystals. The ${ }^{1} \mathrm{H}$ NMR spectrum of $\mathbf{9 b}$ features an olefinic resonance signal at $5.96 \mathrm{ppm}$ suggesting the dearomatization of the aryl group and the formation of a cyclohexadiene moiety. This assumption was confirmed by a single crystal X-ray diffraction analysis. Dication $\mathbf{9 b}$ is a symmetrical dimer of 2-oxaspiro[4.5]deca-3,6,9-triene-1-one units, connected at their C8 position (Figure 3). Its formation suggests that dioxolyl radical $\mathbf{7 b}$ undergoes a ring opening through $\mathrm{C}-\mathrm{O}$ bond cleavage to generate vinyl radical $\mathbf{1 0 b}$ (Scheme 4). This latter undergoes a spiro-cyclization to afford cyclohexadienyl radical $\mathbf{1 1 b}$, which is apparently persistent enough to build-up in solution and dimerizes.

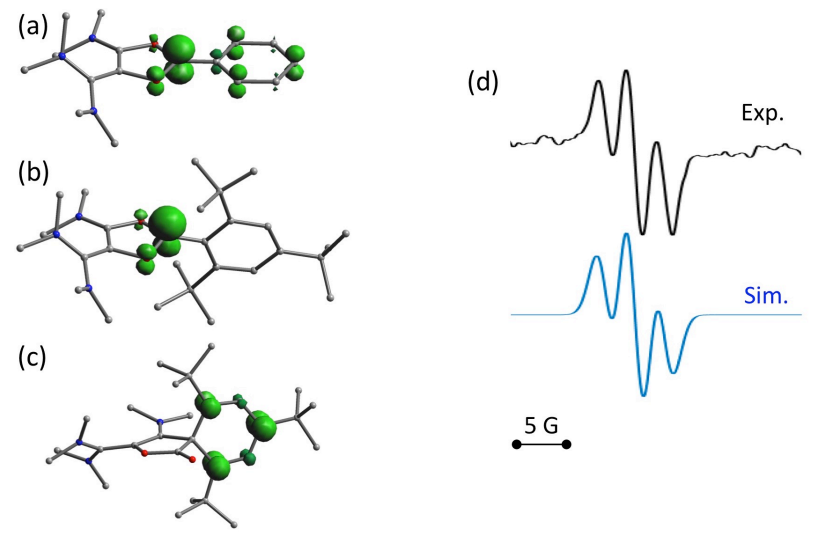

Figure 4: Representation of computed Mulliken spin densities for, (a) 6a, (b) 6d and (c) 11d; (d) Experimental X-band isotropic EPR spectrum at room temperature in acetonitrile after reduction of $\mathbf{6} \mathbf{d}$ (top, in black), the simulated spectrum (bottom, in blue) was obtained with a Lorentzian line-broadening parameter of 0.25 and an hyperfine constant $a\left({ }^{1} \mathrm{H}\right)$ of $8.0 \mathrm{MHz}(2$ nuclei).

In the case of the reduction of $\mathbf{6 c}$, which features an even more bulky 2,6-dimethyl-4-tertbutylphenyl group, the crude mixture yielded very complex NMR spectra, suggesting that the corresponding radical $7 c$ evolved following multiple pathways. Nevertheless, a small amount of pure material could be isolated as a crystalline solid, which was attributed to dimer $\mathbf{8 c}$. Indeed, although no suitable crystals for X-ray diffraction could be obtained, NMR 
data are clearly reminiscent of bis(dioxole) $\mathbf{8 a}$, including signals for untouched aryl substituents and a peak in ${ }^{13} \mathrm{C}\left\{{ }^{1} \mathrm{H}\right\} \mathrm{NMR}$ at $115.9 \mathrm{ppm}$ for $\mathrm{C} 1$ and $\mathrm{C}^{\prime}$ carbons, which are linking the two monomeric units (8a: $111.2 \mathrm{ppm}$ ). This attribution is also supported by HR-MS analysis, which is consistent with a dicationic dimer.

DFT calculations indicate that radicals $7 a-c$ have almost identical electronic structures. Most of the Mulliken spin density is centered on the $\mathrm{C} 1$ carbon atom (51-53\%, see Table 2 and Figure $4 \mathrm{a})$, the rest being spread over the aryl group (30-33\%), and the two oxygen atoms (12-13\%). Similarly to the corresponding dioxolium carbeniums, the $p-$ systems of the dioxolyl and the vinamidinium moities poorly interact, the latter bearing less than $5 \%$ spin density. Dioxolyl 7a (Aryl = phenyl), vinyl 10a and cyclohexadienyl radicals 11a were found very close in energy and it is likely that the three forms co-exist in solution. In the case of bulkier aryl substituents, the balance is more shifted towards the cyclohexadienyl forms $\mathbf{1 1} \mathbf{b}-\mathbf{c}$. Note that the isolated products $\mathbf{8 a}, \mathbf{c}$ and $\mathbf{9 b}$ do not correspond to the dimer of the most stable radical form but to the overall most stable dimer, thus suggesting that dimerization is essentially under thermodynamic control. Interestingly, the introduction of methyl ortho-subsituents is not detrimental to the formation of dimers $8 a-c$ from radicals $7 a-c$, the dimerization being even more exergonic for $7 \mathbf{b}, \mathbf{c}\left(D G\right.$ about $-70 \mathrm{kcal}^{\mathrm{mol}} \mathrm{l}^{-1}$ ) than for $7 \mathbf{a}\left(D G=-51 \mathrm{kcal}^{\mathrm{mol}} \mathrm{l}^{-1}\right)$. Similarly, the formation of dimer $9 \mathbf{b}$ from cyclohexadienyl radical $\mathbf{1 1 b}$ is predicted to be more exergonic than the formation of 9a from 11a. However, the para tert-butyl group in 11c is clearly prejudicial to the formation of the corresponding dimer $9 \mathbf{c}\left(D G=-6 \mathrm{kcal}\right.$. $\mathrm{mol}^{-}$ ${ }^{1}$ only). In line with this trend, radicals $\mathbf{7 d}$ and $\mathbf{1 1 d}$, which stem from dioxolium $\mathbf{6 d}$ with a 2,4,6-tri(tertbutyl)phenyl substituent, should not dimerize. Indeed, the formation of dimer $9 \mathbf{d}$ from 11d was found slightly endergonic and no minimum on the hypersurface of energy could be found for the putative dimer $\mathbf{8 d}$. Note that $\mathbf{7 d}$ is also predicted to be fundamentally different from 7a-c. The aryl group is not conjugated with the rest of the p-system anymore and does not feature significant spin density, $80 \%$ of it being now localized on the carbenium center C1 (Table 2 and Figure $4 \mathrm{~b}$ ). The latter has no planar environment anymore (sum of bond angles around C1 in $7 \mathrm{~d}: 350.6^{\circ}$, in $\left.7 \mathrm{a}-\mathrm{c}:>359.9^{\circ}\right)$, indicating an increased $\mathrm{sp}^{3}$ character. This illustrates the key role of the aryl group in the stabilization of dioxolyl radicals through spin delocalization. In addition, not only is $\mathbf{7 d}$ poorly stabilized, but the cyclohexadienyl form is only $-12 \mathrm{kcal}^{\mathrm{mol}} \mathrm{m}^{-1}$ lower in energy and is likely to be highly reactive as well.

In order to experimentally assess the fate of these radicals, we examined the reduction of dioxolium $6 \mathbf{d}$ with half an equivalent of zinc(0) powder. EPR monitoring of the reaction showed the appearance of a 1:2:1 triplet, corresponding to an hyperfine coupling constant $a=8 \mathrm{MHz}$ with two equivalent $1 / 2 \operatorname{spins}^{34}$ (Figure $4 \mathrm{~d}$ ). This value is in perfect agreement with the expected spectrum for 11d. In particular, DFT calculations predict that this organic p-radical should only feature significant isotropic hyperfine coupling constants with the two hydrogen atoms in meta position of the aryl group, with a computed value $a\left({ }^{1} \mathrm{H}\right)$ of about $9 \mathrm{MHz}$. Though persistent at room temperature, the EPR signal evolved after few hours into a more complex unsymmetrical bandshape, indicating a mixture of radical species, and finally faded away (see supporting information). Unsurprisingly, all attempts to isolate $\mathbf{1 1 d}$ failed. Ultimately, known indanone $\mathbf{1 2}^{35}$ was isolated from the crude mixture in $30 \%$ yield (Scheme 4). Note that, at a pinch, the formation of dimers $\mathbf{8 a , c}$ could have been the result of an ionic mechanism. However, the formation of $\mathbf{9 b}$, the observation of radical $\mathbf{1 1 d}$, as well as DFT results as a whole, definitely support radical pathways, stemming from a one-electron reduction of the dioxoliums.

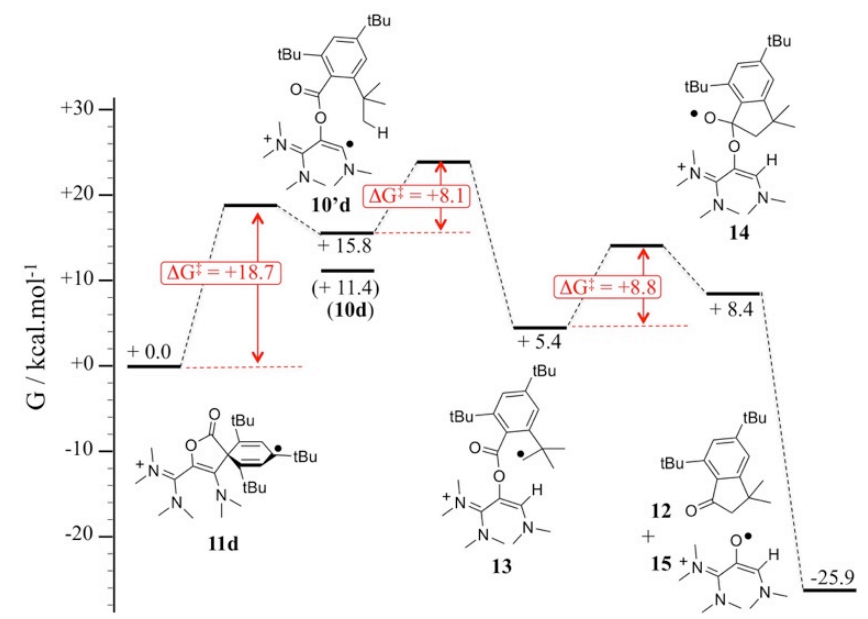

Figure 5: Computed mechanism for the formation of indenone 12 from $11 \mathbf{d}$ at the; $u \omega B 97 X D / 6-311 g(d, p) / P C M(a c e t o n i t r i l e)$ level of theory relative Gibbs energies of intermediates and Gibbs energies of activation.

We propose a mechanism for the decay of $\mathbf{1 1 d}$ into $\mathbf{1 2}$, which is supported by DFT investigations (Figure 5). The rate-determining step of the process is the ring opening of $11 \mathrm{~d}$, yielding vinyl radical $10 \mathrm{~d}^{\prime}\left(D G^{\ddagger}=+18.7 \mathrm{kcal}^{\prime} \mathrm{mol}^{-1}\right)$. The latter is only $+4.4 \mathrm{kcal} \mathrm{mol}^{-1}$ higher in energy than the most stable conformer $10 \mathrm{~d}$. It features the relevant conformation for a hydrogen shift from an ortho tert-butyl group $\left(\mathrm{DG}^{\ddagger}=+8.1 \mathrm{kcal} . \mathrm{mol}^{-1}\right)$. The resulting alkyl 
radical 13 adds intramolecularly to the carbonyl group $\left(D G^{\ddagger}=+8.8 \mathrm{kcal}^{\circ} \mathrm{mol}^{-1}\right)$, yielding five-membered ring 14, which undergoes a barrier-less homolytic $\mathrm{C}-\mathrm{O}$ bond breaking to afford indanone 12 and radical $\mathbf{1 5}$. Note that we previously showed that so-called oxyallyl radical cations, which are parented to 15 , are remarkably stabilized and could even be highly air-persistent. ${ }^{10 a, c ; 25 a, d, e}$ Although it appears that $\mathbf{1 5}$ evolve further in the reaction conditions, it is likely that it contributes to the transiently observed EPR spectrum upon decay of 11d. However, we couldn't obtain an unambiguous simulation for the EPR bandshapes by only considering a mixture of the cyclohexadienyl and oxyallyl radicals. This suggested the formation of a more complex mixture of paramagnetic species.

\section{Conclusion}

Dicationic dioxoliums $\mathbf{6 a - d}$ were readily synthesized from acetamides $\mathbf{2 a - d}$. All spectroscopic and structural data indicate a poorly aromatic five-membered ring and a modest interaction between the p-systems of the vinamidinium and carbenium moieties. This situation is reminiscent of that of the neutral borate-based zwitterions from Stephan et al., ${ }^{21 \mathrm{~b}}$ which were the only non-stabilized dioxoliums to have been previously structurally characterized by $\mathrm{X}$-ray analysis.

The fate of 6a-d upon reduction highly depends on the aryl substituent. All dioxolyl radicals $\mathbf{7 a - d}$ can undergo a ring-opening, which is reminiscent of the Surzur-Tanner rearangement of b-(acyloxy)alkyl radicals. They are in equilibrium with the resulting vinyl radical forms 10a-d and their spiro-cyclization products, the cyclohexadienyl radicals 11a-d. In the case of a bulky tri(tert-butyl)phenyl aryl group (7d), dimerization processes are disfavored. The radical essentially exists in the cyclohexadienyl form 11d, which was observed at room temperature by EPR spectroscopy.

DFT studies show that spin-delocalization on the aryl group plays a major role in the stabilization of dioxolyl radicals, with only second-order effects of the O-substituents. As a matter of fact, dioxolyl radicals 7 a-c could be depicted as well as benzyl radicals with ancillary O-substituents: more than $30 \%$ of spin density is found on the fully conjugated aryl groups, only $12-13 \%$ being spread on the two oxygen atoms. In $\mathbf{7 d}$, the bulky tert-butyl ortho-substituents twist away the p-systems and prevent this delocalization. The radical is highly localized, with more than $80 \%$ of spin density on one carbon atom, which features some $\mathrm{sp}^{3}$ hybridation.

Finally, although DFT WB97XD/6-311g(d,p)/PCM calculations could fairly account for the experimental data and observations of this work, it is too early to fully ascertain their accuracy. We are actually considering experimental gas phase studies with a modified QhQ mass spectrometer to better calibrate DFT level of theory and further explore the uncharted territory of the reactivity of these species.

\section{Acknowledgements}

This work was supported by the French National Agency for Research (ANR-14-CE06-0013-01 and ANR-17-ERC20015). The authors are grateful to the IR-RPE CNRS FR3443 RENARD network for EPR facilities. Thanks are due to the "Centre de Calcul Intensif en Chimie de Grenoble" and the University of Grenoble-Alpes, including the PoleAgir fund, and partial support from Labex ARCANE and CBH-EUR-GS (ANR-17-EURE-0003). The authors also thank the ICMG Chemistry Nanobio Platform of Grenoble, especially $\operatorname{Dr}$ C. Phillouze and N. Altounian for the X-ray crystallographic structure determination of compounds $\mathbf{5}$.

\section{References}

1 a) R. W. Taft, R. H. Martin and F. W. Lampe, J. Am. Chem. Soc., 1965, 87, 2490; b) F. Bernardi, A. Bottoni and A. Venturini, J. Am. Chem. Soc., 1986, 108, 5395; c) J. Kapp, C. Schade, A. M. El-Nahas and P. von R. Schleyer, Angew. Chem. Int. Ed. Engl., 1996, 35, 2236; d) H. Grützmacher and C. M. Marchand, Coord. Chem. Rev., 1997, 163, 287; e) J. Rissler, M. Hartmann, C. M. Marchand, H. Grützmacher and G. Frenking, Chem. Eur. J., 2001, 7, 2834; f) H. F. Fang, Z. Wang and X. Fu, Coord. Chem. Rev., 2017, $344,214$.

2 a) G. A. Olah, Angew. Chem. Int. Ed., 1993, 32, 767; b) G. A. Olah, Angew. Chem. Int. Ed., 1995, 34, 1393; c) G. A. Olah, J. Org. Chem., 2001, 66, 5943.

3 F. G. Bordwell, Acc. Chem. Res., 1988, 21, 456.

4 a) H. G. Viehe, R. Mértnyi, L. Stella and Z. Janousek, Angew. Chem. Int. Ed. Engl., 1979, 18, 917; b) H. G. Viehe, Z. Janousek, R. Mértnyi and L. Stella, Acc. Chem. Res., 1985, 18, 148; c) H. Zipse, Top. Curr. Chem., 2006, 263, 163; d) Substituent Effects in Radical Chemistry, (Eds. V. H. Veihe, Z. Janousek and R. Mértnyi) Riedell, Boston, 1986; e) A. R. Katritzky, M. C. Zerner and M. M. Karelson, J. Am. Chem. Soc., 1986, 108, 7213; f) D. J. Pasto, J. Am. Chem. Soc., 1988, 110, 8164; g) F. G. Bordwell and T. -Y. Lynch, J. Am. Chem. Soc., 1989, 111, 7558; h) M. L. Coote and A. B. Dickerson, Aust. J. Chem., 2008, 61, 163; i) A. S. Menon, D. J. Henry, T. Bally and L. Radom, Org. Biomol. Chem., 2011, 9, 3636; j) M. L. Coote, C. Y. Lin, A. L. Beckwith and A. A. Zavitsas, Phys. Chem. Chem. Phys., 2010, 12, 9597.

5 For kinetic and thermodynamic metrics of substituent effects, see also: a) H. O. Pritchard and H. A. Skinner, Chem. Rev., 1955, 55, 745; b) J. Mullay, in Electronegativity. Structure and Bonding, Vol. 66 (Eds. K. D. Sen and C. K. Jørgensen), Springer, Berlin, 1987; c) C. Hansch, A. Leo and W. Taft, Chem. Rev., 1991, 91, 165; d) H. Mayr and A. R. Ofial, Acc. Chem. Res., 2016, 49, 952.

6 M. A. Kouskoulli, D. M. Smith and A. V. Nicolaides, J. Mol. Struct.: Theochem, 2007, 811, 355.

7 For pioneering studies, see: a) G. A. Olah, M. Calin and D. H. O'Brien, J. Am. Chem. Soc., 1967, 89, 3586; b) G. A. Olah and A. M. White, J. Am. Chem. Soc., 1967, 89, 3591; c) G. A. Olah and A. M. White, J. Am. Chem. Soc., 1968, 90, 1884. 
8 Further features are usually required. Aromatic heterocyclic pyriliums, among which anthocyanidin-based natural dyes, are regarded as the prototypical stable O-substituted carbeniums. See for examples: a) D. W. Hill, Chem. Rev., 1936, 19, 27; b) G. A. lacobucci and J. G. Sweeny, Tetrahedron, 1983, 39, 3005; c) F. Pina, M. J. Melo, C. A. T. Laia, A. J. Parola and J. C. Lima, Chem. Soc. Rev., 2012, 41, 869.

9 For preparation of simple iminiums salts, see: a) A. Ahond, A. Cave, C. Kan-Fan, H.-P. Husson, J. de Rostolan and P. Pottier, J. Am. Chem. Soc., 1968, 90, 5622; b) H. Voltz and H. H. Kiltz, Tetrahedron, 1970, 26, 1917; c) N. Holy, R. Fowler, E. Burnett and R. Lorenz, Tetrahedron, 1979, 35, 613; d) U. Jahn and W. Schroth, Tetrahedron Lett., 1993, 34, 5863.

10 a) D. Martin, C. E. Moore, A. L. Rheingold and G. Bertrand, Angew. Chem. Int. Ed., 2013, 52, 7014; b) J. K. Mahoney, D. Martin, C. Moore, A. Rheingold and G. Bertrand, J. Am. Chem. Soc., 2013, 135, 18766; c) J. K. Mahoney, D. Martin, F. Thomas, C. Moore, A. L. Rheingold and G. Bertrand, J. Am. Chem. Soc., 2015, 137, 7519; d) C. L. Deardorff, E. R. Sikma, C. P. Rhodes and T. W. Hudnall, Chem. Commun., 2016, 52, 9024; e) J. K. Mahoney, R. Jazzar, G. Royal, D. Martin and G. Bertrand, Chem. Eur. J., 2017, 23, 6206; f) V. Regnier, E. A. Romero, F. Molton, R. Jazzar, G. Bertrand and D. Martin, J. Am. Chem. Soc., 2019, 141, 1109.

11 See also: a) T. H. Koch, J. A. Olesen and J. DeNiro, J. Am. Chem. Soc., 1975, 97, 7285; b) R. J. Himmelsbach, A. D. Barone, D. L. Kleyer and T. H. Koch, J. Org. Chem., 1983, 48, 2989; c) G. Gaudiano, K. Sweeney, R. C. Haltiwanger and T. H. Koch, J. Am. Chem. Soc., 1984, 106, 7628; d) O. Benson Jr., S. H. Demirdji, R. C. Haltiwanger and T. H. Koch, J. Am. Chem. Soc., 1991, 113, 8879; e) O. Benson Jr., G. Gaudiano, R. C. Haltiwanger and T. H. Koch, J. Org. Chem., 1988, 53, 3036; f) D. L. Kleyer, R. C. Haltiwanger and T. H. Koch, J. Org. Chem., 1983, 48, 147; g) F. Welle, S. P. Verevkin, M. Keller, H.-D. Beckhaus and C. Ruchardt, Chem. Ber., 1994, 127, 697; h) I. Nakanishi, S. Itoh and S. Fukuzumi, Chem. Eur. J., 1999, 5, 2810; i) M. Frenette, C. Aliaga, E. Font-Sanchis and J. C. Scaiano, Org. Lett., 2004, 6, 2579; j) L. Jin, M. Melaimi, L. Liu and G. Bertrand, Org. Chem. Front., 2014, 1, 351; k) S. Styra, M. Melaimi, C. E. Moore, A. L. Rheingold, T. Augenstein, F. Breher and G. Bertrand, Chem. Eur. J., 2015, $21,8441$.

12 Note also that even parented oxygen equivalents of tetrathiafulvalene radical cations cannot be isolated: a) T. Nogami, K. Tanaka and A. Kobayahi, Synth. Metals, 2001, 120, 755; b) T. Kojima, K. Tanaka, T. Ishida and T. Nogami, J. Org. Chem., 2004, $69,9319$.

13 U. Wille, J. Org. Chem., 2006, 71, 4040.

14 U. Wille, Chem. Rev., 2013, 113, 813.

15 For closely related reactions, see also: a) U. Wille and C. Plath, Liebigs Ann. Recl., 1997, 111; b) U. Wille and L. Lietzau, Tetrahedron, 1999, 55, 10119; c) U. Wille, Org. Lett., 2000, 2, 3485; d) L. Lietzau and U. Wille, Heterocycles, 2001, 55, 377 ; e) U. Wille, Chem. Eur. J., 2002, 8, 340; f) U. Wille, J. Am. Chem. Soc., 2002, 124, 14; g) C. Jargstorff, U. Wille, Eur. J. Org. Chem., 2003, 2173; h) U. Wille, J. Phys. Org. Chem., 2011, 24, 672.

16 a) C. Brunton, K. U. Ingold, B. P. Roberts, A. L. J. Beckwith and P. J. Krusic, J. Am. Chem. Soc., 1977, 99, 3177; b) C. Gaze and B. C. Gilbert, J. Chem. Soc., Perkin Trans. 2, 1978, 235; c) C. Gaze and B. C. Gilbert, J. Chem. Soc., Perkin Trans. 2, 1979, 763; d) V. Malatesta and K. U. Ingold, J . Am. Chem. Soc., 1981, 103, 609; e) A. L. J. Beckwith and C. J. Easton, J. Am. Chem. Soc., 1981, 103, 615; f) S. Deycard, J. Lusztyk, K. U. Ingold, F. Zerbetto, M. Z. Zgierski and W. Siebrand, J. Am. Chem. Soc., 1990, 112, 4284; g) A. J. Fielding, P. Franchi, B. P. Roberts and T. M. Smits, J. Chem. Soc., Perkin Trans. 2, 2002, 155.

17 a) J. M. Surzur and P. Teissier, C. R. Acad. Sci. Fr. Ser. C, 1967, 264, 1981; b) D. D. Tanner and F. C. P. Law, J. Am. Chem. Soc. 1969, 91, 7535; c) A. L. J. Beckwith, D. Crich, P. J. Duggan and Q. Yao, Chem. Rev., 1997, 97, 3273.

18 a) L. R. C. Barclay, D. Griller and K. U. Ingold, J. Am. Chem. Soc., 1982, 104, 4399; b) S. Saebo, A. L. J. Beckwith and L. Radom, J. Am. Chem. Soc., 1984, 106, 5119; c) L. R. C. Barclay, J. Lusztyk and K. U. Ingold, J. Am. Chem. Soc., 1984, 106, 1793 ; d) D. Crich and D.-H. Suk, Can. J. Chem., 2004, 82, 75; e) H. Zipse, J. Am. Chem. Soc., 1997, 119, 1087; f) E. Lacôte and P. Renaud, Angew. Chem. Int. Ed., 1998, 37, 2259.

19 a) W. T. Evanochenko and P. Shevlin, J. Org. Chem., 1979, 44, 4426; b) F. Shahidi and T. T. Tidwell, Can. J. Chem., $1982,60,1092$.

20 a) A. D. Allen, T. Kitamura, R. A. McClelland, P. J. Stang and T. T. Tidwell, J. Am. Chem. Soc., 1990, 112, 8873; b) T. Schwier, A. W. Sromek, D. M. L. Yap, D. Chernyak and V. Gevorgyan, J. Am. Chem. Soc., 2007, 129, 9868.

21 The only examples of 1,3-dioxolium compounds without charge-stabilizing atoms at C-2 are limited to: a) W. Lorenz and G. Maas, J. Org. Chem., 1987, 52, 375; b) M. M. Hansmann, R. L. Melen, F. Rominger, A. S. K. Hashmi and D. W. Stephan, Chem. Commun., 2014, 50, 7243.

22 a) H. Gross and J. Rusche, Angew. Chem., Int. Ed., 1964, 3, 511; b) K. Dimroth, P. Heinrich and K. Schromm, Angew. Chem., Int. Ed., 1965, 4, 873; c) H. Volz and G. Zimmermann, Tetrahedron Lett., 1970, 3597.

23 a) G. A. Olah and A. M. White, J. Am. Chem. Soc., 1968, 90, 1884; b) G. A. Olah and J. L. Grant, J. Org. Chem., 1977, 42, 2237; c) U. Timm, U. Plücken, H. Petersen and H. Meier, J. Heterocycl. Chem., 1979, 16, 1303; d) H. Mayr and U. von der Brüggen, Chem. Ber., 1988, 121, 339.

24 a) P. R. Moses, J. Q. Chambers, J. O. Sutherland and D. R. Williams, J. Electrochem. Soc., 1975, 122, 608; b) R. D. Braun and D. C. Green, J. Electroanal. Chem., 1977, 79, 381; c) G. Maas and B. Singer, Chem. Ber., 1983, 116, 3639.

25 a) V. Regnier, F. Molton, C. Philouze and D. Martin, Chem. Commun., 2016, 52, 11422 ; b) V. Regnier, Y. Planet, C. E. Moore, J. Pecaut, C. Philouze and D. Martin, Angew. Chem. Int. Ed., 2017, 56, 1031 ; c) M. Tripathi, V. Regnier, C. Lincheneau and D. Martin, New. J. Chem., 2017, 41, 15016; d) M. Devillard, V. Regnier, M. Tripathi and D. Martin, J. Mol. Struct., 2018, 1172, 3; e) M. Tripathi, V. Regnier, Z. Ziani, M. Devillard, C. Philouze and D. Martin, RSC Advances, 2018, 8, 38346; f) V. Regnier and D. Martin, Org. Chem. Front., 2015, 2, 1536.

26 a) Z. Janousek and H. G. Viehe, Angew. Chem. Int. Ed. Engl., 1971, 10, 574; b) H. G. Viehe, Z. Janousek, R. Gompper and D. Lach, Angew. Chem. Int. Ed. Engl., 1973, 12, 566; c) A. Fürstner, M. Alcazaro and H. Krause, Org. Synth., 2009, 298.

27 CCDC 1898554-1898565 contain the supplementary crystallographic data for this paper. These data are provided free of charge by the Cambridge Crystallographic Data Centre.

28 a) H. Paulsen and R. Dammeyer, Chem. Ber., 1973, 106, 2324; b) H. Paulsen and R. Dammeyer, Chem. Ber., 1976, 109, 1837; c) M. R. Caira and J. F. de Wet, Acta Cryst., 1981, B37, 709 ; d) R. F. Childs, R. M. Orgias, C. J. L. Lock and M. Mahendran, Can. J. Chem., 1993, 71, 836.

29 a) A. O. Doroshenko, T. V. Sakhno and A. V. Kyrychenko, Spect. Letters, 2002, 345, 171; b) D. C. Graham, K. J. Cavell and B. F. Yates, Dalton Trans., 2007, 4650; c) J. Zhang, J. Fu, X. Su, X. Qin, M. Zhao and M. Shi, Chem. Commun., 2012, 48, 9625; d) R. L. Melen, M. M. Hansmann, A. J. Lough, A.S K. Hasmi and D. W. Stephan, Chem. Eur. J., 2013, 19, 11928.

30 DFT calculations were performed using the program package Gaussian09: Gaussian 09, Revision 4.2.0, M. J. Frisch, G. W. Trucks, H. B. Schlegel, G. E. Scuseria, M. A. Robb, J. R. Cheeseman, G. Scalmani, V. Barone, B. Mennucci, G. A. Petersson, H. Nakatsuji, M. 
Caricato, X. Li, H. P. Hratchian, A. F. Izmaylov, J. Bloino, G. Zheng, J. L. Sonnenberg, M. Hada, M. Ehara, K. Toyota, R. Fukuda, J. Hasegawa, M. Ishida, T. Nakajima, Y. Honda, O. Kitao, H. Nakai, T. Vreven, J. A. Montgomery, Jr., J. E. Peralta, F. Ogliaro, M. Bearpark, J. J. Heyd, E. Brothers, K. N. Kudin, V. N. Staroverov, R. Kobayashi, J. Normand, K. Raghavachari, A. Rendell, J. C. Burant, S. S. Iyengar, J. Tomasi, M. Cossi, N. Rega, J. M. Millam, M. Klene, J. E. Knox, J. B. Cross, V. Bakken, C. Adamo, J. Jaramillo, R. Gomperts, R. E. Stratmann, O. Yazyev, A. J. Austin, R. Cammi, C. Pomelli, J. W. Ochterski, R. L. Martin, K. Morokuma, V. G. Zakrzewski, G. A. Voth, P. Salvador, J. J. Dannenberg, S. Dapprich, A. D. Daniels, . Farkas, J. B. Foresman, J. V. Ortiz, J. Cioslowski and D. J. Fox, Gaussian, Inc. Wallingford CT, 2009. See supplementary information for further details.

31 For a seminal example and discussions, see: a) S. Grimme and P. R. Schreiner, Angew. Chem. Int. Ed., 2011, 50, 12639; b) S. Grimme, Angew. Chem. Int. Ed., 2006, 45, 4460.

32 J.-D. Chai and M. Head-Gordon, Phys. Chem. Chem. Phys., 2008, 10, 6615

33 S. Grimme, J. Comp. Chem., 2006, 27, 1787.

34 The experimental EPR spectrum was fitted with the EasySpin simulation package: S. Stoll and A. Schweiger, J. Magn. Reson., 2006, 178, 42.

35 P. J. Wagner, B.-S. Park, M. Sobczak, J. Frey and Z. Rappoport, J. Am. Chem. Soc., 1995, 117, 7619.

36 A. W. Ehlers, M. Lutz, J. C. Slootweg and K. Lammertsma, Angew. Chem. Int. Ed., 2014, 53, 12836.

37 H. G. Emblem, K. Hargreaves and C. E. Oxley, J. Appl. Chem., 1968, 18, 97.

38 C. Hering-Junghans, A. Schulz, M. Thomas and A. Villinger, Dalton Trans., 2016, 45, 6053.

39 J. E. Field, T. J. Hill and D. Venkataraman, J. Org. Chem., 2003, 68, 6071. 